\title{
Adult body height, self perceived health and mortality in the Swedish population
}

\author{
A MARIA NYSTRÖM PECK ${ }^{1}$ AND DENNY H VÅGERÖ ${ }^{2}$ \\ From ${ }^{\prime}$ the Department of Social Medicine, Huddinge University Hospital, Huddinge, Sweden; ${ }^{2}$ the Department of \\ Epidemiology, Institute of Environmental Medicine, Karolinska Institute, Stockholm, Sweden; and the Institute of \\ Social Research, University of Stockholm, Stockholm, Sweden.
}

\section{ABSTRACT}

Study objective: The purpose of the study was to examine adult body height as an indicator of general health.

Design: The study was a survey of a randomly selected sample of the adult Swedish population obtained by the Swedish National Central Bureau of Statistics.

Participants: The sample studied was identified in 1980-81 and comprised 14757 persons aged 16-74. Of these, $12695(86 \%)$ consented to interview.

Measurements and main results: Information was obtained on adult height, socioeconomic status in childhood and adult life, self perceived health, self reported longstanding illness, and mortality⿳亠丷厂 during a six year follow up. The numbers of people in three height groups who considered their general health as bad, who reported any longstanding illness or who died during the follow up were compared with the expected numbers in the same groups. The number of persons with reduced health and the number of deaths was larger than expected in the shortest height group. The excess risk of dying in the shortest group (about $20 \%$ higher compared to the tallest group) was reduced but not eliminated when present and childhood socioeconomic group was taken into account. Coronary heart disease mortality in particular was linked to height. The shortest group of men and women reported the largest proportion with bad general health and longstanding illness. For the latter the differences between height groups disappeared after controlling for present socioeconomic status. Conclusions: There is a detectable excess risk of morbidity and mortality from being short. Assuming that the childhood environment is an important determinant of adult stature it is also important for adult health.

Body height has been used as an indicator of poor nutrition among children but has also occasionally been studied in adult groups in relation to living conditions. ${ }^{1-3}$ Earlier we have shown that adult body height is correlated with childhood socioeconomic group in the Swedish population. ${ }^{4}$ We then discussed, as others have before us, ${ }^{13}$ the possibility of using body height as an indicator of general health or susceptibility to disease. Height has also been suggested as a supplement to other measures of health in population studies. ${ }^{5}$ In order to validate this suggestion on a Swedish sample, we wanted to study the connection between adult body height on the one hand, and some measures of health on the other. We chose three different measures, ie, mortality, self perceived health in general and self reported longstanding illness. At least two of these, mortality and longstanding illness, have been found to covary with height. ${ }^{1-36}$ In the cases where mortality has been studied, special attention was paid to cardiovascular diseases.

\section{Methods}

POPULATION UNDER STUDY

Since 1974 the National Central Bureau of Statistics (Statistics, Sweden) has carried out annual interviews about living conditions, looking, for example, at health, employment, housing, social relations, and personal finance. The sample size is $8-10000$ persons per year randomly drawn from the adult population. Our study used the answers to the interviews carried 
out in 1980-81. In this analysis we have used seven out of approximately 150 questions. These comprised one question about the respondent's body height and one about his/her father's occupation during childhood of the respondent (the wording of these two can be found in ${ }^{4}$ ). We also used the questions "What position do you hold at your place of work?" ("Vad kallas den befattning Ni har på arbetsplatsen?") and "Can you give a short description of your tasks?" (Kan Ni kortfattat beskriva Era arbetsuppgifter?"). These two questions were used to establish the occupation of the respondent. Persons not employed at the time of interview were coded according to earlier work experience. Those never employed formed a separate group. We then used three questions about the health of the interviewee: "How do you consider your own health in general? As good, bad or something in between?" ("Hur bedömer Ni Ert allmänna hälsotillstånd?"), "Do you suffer from any longstanding illness or handicap?" ("Har Ni någon långvarig sjukdom, besvär efter olycksfall, något handikapp eller annan svaghet?") and "Do you take any medicine regularly?" ("Tar $\mathrm{Ni}$ regelbundet medicin för någonting?"). Of the women $5.5 \%$ and of the men $4.9 \%$ considered their health as bad, $78.2 \%$ (men) and $75.1 \%$ (women) as good, and $16.8 \%$ (men) and $19.3 \%$ (women) as something in between. As many as $41.9 \%$ of the women and $38.3 \%$ of the men suffered from a longstanding illness or a handicap and/or took medicines regularly.

The sample in 1980-81 consisted of 14757 persons aged 16 to 74 . Of these, $86.0 \%$ consented to the interview, ie, 12695 individuals. In some of the interviews the answer to one or more of the questions used in this study is missing. The results in the different tables may therefore be based on different numbers of interviews. A comprehensive discussion of the survey methods and the statistical precision of the results of the survey can be found elsewhere. ${ }^{7}$

The occupation of the respondent's father was classified into seven socioeconomic groups according to a classification system used by Statistics, Sweden since $1974 .^{8}$ For $0.9 \%$ no code could be given. The occupation of the respondent herself/himself was coded in the same seven groups. Students formed a separate group. Non-classifiable persons $(5.0 \%$ of the sample) also constituted a separate group.

The register of those who consented to the interview was linked to the Cause of Death Register for the period 1980-86. Thus the register included 345 men and 197 women who had died during the follow up. For these persons the underlying cause of death was known as well as the date of death.

\section{METHODS OF ANALYSIS}

Three height groups were defined so that each included one third of the male or female population.
Thus, for men, the short group was defined as those of height 145 to $174 \mathrm{~cm}$, the medium group 175 to $180 \mathrm{~cm}$, and the tall group 181 to $206 \mathrm{~cm}$. For women the short group were those between 129 and $162 \mathrm{~cm}$, the medium group 163 to $167 \mathrm{~cm}$, and the tall group 168 to $186 \mathrm{~cm}$.

For each height group the observed number of deaths was compared to the expected number. The expected numbers were based on the number of deaths in the whole sample. They were calculated separately for men and women and were specified for each five year age group, and in some cases for own and/or father's socioeconomic group. The total expected value was obtained by summarising over strata. Thus the standardised mortality could be calculated as the ratio of observed to expected number of deaths for each gender and height group. For each standardised mortality ratio a $95 \%$ confidence interval was calculated. ${ }^{9}$ As both height and mortality are associated with socioeconomic group, we tried to control for confounding from both the respondent's present socioeconomic group and that of his/her childhood. This was done by standardisation for these two variables.

In the same way as described above, the expected number of persons with reduced health was calculated and a standardised morbidity ratio for self perceived general health and for longstanding illness was calculated.

In addition we estimated the proportion of deaths in the age groups 20-79 that could be avoided if the death rate among those of short or medium height was the same as for the tall third, controlling for present socioeconomic group. ${ }^{10}$ For comparison the proportion of deaths attributable to present socioeconomic group was also calculated.

\section{Results}

Table 1 presents standardised mortality ratios for three different height groups in the Swedish population for men, for women and for men and women combined. Comparing the age standardised mortality ratio for the short group of men and women to that of the tall men and women, it can be seen that the short group had about a $20 \%$ excess risk of dying during the follow up period. This difference was present among both men and women. The difference was slightly reduced when taking into account present socioeconomic group as well as when taking into account present and childhood socioeconomic groups simultaneously. In both instances, we were still left with some excess risk (15\%). The risk of dying from cardiovascular diseases in general and from coronary heart disease was also calculated. In these cases, the differences between the height groups were larger, short men having a standardised mortality ratio of 115 
Table 1 Body height and mortality. Observed (Obs) number of deaths, and mortality ratios standardised for age (SMRI), for age and present socioeconomic group (SMR2) and for age, present and childhood socioeconomic group simultaneously (SMR3). SMRs are means with (95\% confidence intervals).

\begin{tabular}{lrcrr}
\hline $\begin{array}{l}\text { Height } \\
\text { group }\end{array}$ & Obs & SMR1 & SMR2 & SMR3 \\
\hline \multicolumn{5}{c}{ Men } \\
Short & 158 & $107(91-125)$ & $104(89-122)$ & $102(87-119)$ \\
Medium & 109 & $98(80-118)$ & $100(82-121)$ & $103(84-124)$ \\
Tall & 59 & $88(67-113)$ & $87(66-112)$ & $90(68-116)$ \\
& \multicolumn{5}{c}{ Women } \\
$\begin{array}{l}\text { Short } \\
\text { Medium }\end{array}$ & 89 & $110(88-135)$ & $106(86-131)$ & $107(86-132)$ \\
Tall & 55 & $92(69-119)$ & $93(70-122)$ & $95(72-124)$ \\
& 37 & $93(65-128)$ & $96(68-132)$ & $92(65-127)$ \\
Short & 247 & $108(95-122)$ & $105(92-119)$ & $104(91-118)$ \\
Medium & 164 & $96(82-111)$ & $98(83-114)$ & $100(85-116)$ \\
Tall & 96 & $90(73-109)$ & $90(73-110)$ & $91(73-111)$ \\
\hline
\end{tabular}

compared to 79 for tall men for coronary heart disease (table 2) and 109 compared to 83 for the total group of cardiovascular diseases (table 3 ). The standardised mortality ratios for women were 135 compared to 64 for coronary heart disease and 119 to 87 for cardiovascular diseases in general. The differences between the height groups were reduced, but not completely, after standardisation for present and childhood socioeconomic group. For coronary heart disease in particular, a substantial difference still existed after controlling for present socioeconomic group.

Table 2 Body height and mortality from coronary heart disease. Observed (Obs) number of deaths, and mortality ratios standardised for age (SMRI), for age and present socioeconomic group (SMR2) and for age, present and childhood socioeconomic group simultaneously (SMR3). SMRs are means (95\% confidence intervals).

\begin{tabular}{lrcrr}
\hline $\begin{array}{l}\text { Height } \\
\text { group }\end{array}$ & Obs & SMRI & SMR2 & SMR3 \\
\hline \multicolumn{5}{c}{ Men } \\
Short & 61 & $115(89-147)$ & $112(87-144)$ & $107(83-137)$ \\
Medium & 36 & $92(66-127)$ & $94(68-130)$ & $98(71-136)$ \\
Tall & 18 & $79(50-126)$ & $82(52-130)$ & $86(54-136)$ \\
\multicolumn{5}{c}{ Women } \\
Short & 24 & $135(91-201)$ & $134(90-200)$ & $120(80-179)$ \\
Medium & 9 & $72(38-139)$ & $73(38-141)$ & $80(42-154)$ \\
Tall & 5 & $64(27-153)$ & $64(27-152)$ & $74(31-178)$ \\
& \multicolumn{5}{c}{$\begin{array}{c}\text { Men and Women } \text { Wh } \\
\text { Short }\end{array}$} & 85 & $120(97-148)$ & $117(95-145)$ & $110(89-136)$ \\
Medium & 45 & $87(65-117)$ & $89(66-119)$ & $94(70-125)$ \\
Tall & 23 & $76(50-114)$ & $77(51-116)$ & $83(55-125)$ \\
\hline
\end{tabular}

Table 3 Body height and mortality from cardiovascular diseases. Observed (Obs) number of deaths, and mortality ratios standardised for age (SMR1), for age and present socioeconomic group (SMR2) and for age, present and childhood socioeconomic group simultaneously (SMR3). $S M R$ data are means with (95\% confidence intervals).

\begin{tabular}{lcccc}
\hline $\begin{array}{l}\text { Height } \\
\text { group }\end{array}$ & Obs & SMR1 & SMR2 & SMR3 \\
\hline \multicolumn{5}{c}{ Men } \\
Short & 85 & $109(88-135)$ & $106(85-131)$ & $101(81-125)$ \\
Medium & 55 & $97(75-126)$ & $101(78-132)$ & $106(81-138)$ \\
Tall & 27 & $83(57-122)$ & $84(58-123)$ & $88(61-129)$ \\
\multicolumn{5}{c}{ Women } \\
Short & 43 & $119(88-161)$ & $117(87-157)$ & $111(82-150)$ \\
Medium & 21 & $81(53-124)$ & $82(54-126)$ & $86(56-132)$ \\
Tall & 14 & $87(52-147)$ & $90(53-151)$ & $94(55-158)$ \\
& \multicolumn{5}{c}{$\begin{array}{l}\text { Men and Women } \\
\text { Short }\end{array}$} & 128 & $112(94-133)$ & $109(92-130)$ & $104(87-124)$ \\
Medium & 76 & $92(74-115)$ & $95(76-119)$ & $100(79-125)$ \\
Tall & 41 & $85(62-115)$ & $86(63-117)$ & $90(66-122)$ \\
\hline
\end{tabular}

Short men and women tended to classify their present general health as bad to a larger extent than those of medium or tall height (table 4). This tendency was more clear among men, for whom it remained $\mathbb{2}$ even after controlling for the present and childhood socioeconomic group of the interviewed.

Table 4 Body height and general health. Observed (Obs) number of persons perceiving bad health, and morbidity ratios standardised for age (SMorbR1), for age and present socioeconomic group (SMorbR2) and for age, present and childhood socioeconomic group simultaneously (SMorbR3). $S M o r b R$ values are means (95\% confidence intervals).

\begin{tabular}{lrcrr}
$\begin{array}{l}\text { Height } \\
\text { group }\end{array}$ & Obs & SMorbRI & SMorbR2 & SMorbR3 \\
\hline \multicolumn{5}{c}{ Men } \\
Short & 135 & $117(99-138)$ & $109(92-129)$ & $112(95-133)$ \\
Medium & 93 & $92(75-113)$ & $95(78-117)$ & $92(75-113)$ \\
Tall & 57 & $83(64-108)$ & $89(69-116)$ & $89(69-115)$ \\
& \multicolumn{5}{c}{ Women } \\
Short & 143 & $107(91-126)$ & $104(88-123)$ & $105(89-123)$ \\
Medium & 102 & $91(75-111)$ & $92(76-112)$ & $94(77-114)$ \\
Tall & 85 & $101(81-125)$ & $104(84-129)$ & $101(81-124)$ \\
& \multicolumn{5}{c}{ Men and Women } & \\
Short & 278 & $111(99-125)$ & $107(95-120)$ & $108(96-122)$ \\
Medium & 195 & $92(80-106)$ & $94(81-108)$ & $93(81-107)$ \\
Tall & 142 & $93(79-109)$ & $97(83-115)$ & $96(81-113)$ \\
\hline
\end{tabular}

Analysing longstanding illness (table 5) resulted in smaller differences, but here also the group of shorter persons tended to be worse off. However, the group reporting the smallest amount of longstanding illness 
was the medium height group. These differences were reduced, almost completely disappearing for men, when the present socioeconomic group of the interviewed was taken into account.

Table 5 Body height and longstanding illness. Observed (Obs) number of persons with a longstanding illness or who take medicine. Morbidity ratios standardised for age (SMorbR1), for age and present socioeconomic group (SMorbR2) and for age, present and childhood socioeconomic group simultaneously (SMorbR3). SMorbR values are means (95\% confidence intervals).

\begin{tabular}{lrrrrr}
\hline $\begin{array}{l}\text { Height } \\
\text { group }\end{array}$ & Obs & SMorbRI & SMorbR2 & SMorbR3 \\
\hline \multicolumn{7}{c}{ Men } \\
Short & 898 & 104 & $(97-11)$ & $101(95-108)$ & $101(94-108)$ \\
Medium & 804 & 97 & $(90-104)$ & $98(91-105)$ & $98(92-105)$ \\
Tall & 630 & 99 & $(92-107)$ & $101(94-109)$ & $101(94-110)$ \\
& \multicolumn{7}{c}{ Women } \\
Short & 1090 & $107(101-114)$ & $104(98-112)$ & $104(98-110)$ \\
Medium & 832 & 94 & $(87-100)$ & $96(91-101)$ & $95(89-102)$ \\
Tall & 713 & 98 & $(91-105)$ & $100(95-105)$ & $100(92-107)$ \\
& \multicolumn{7}{c}{$\begin{array}{c}\text { Men and Women } \\
\text { Short }\end{array}$} & 1988 & $106(101-110)$ & $104(99-108)$ & $103(98-107)$ \\
Medium & 1636 & 95 & $(91-100)$ & $96(91-101)$ & $97(92-102)$ \\
Tall & 1343 & 98 & $(93-104)$ & $100(95-105)$ & $100(95-106)$ \\
\hline
\end{tabular}

\section{Discussion}

We have studied the connection between adult body height on one hand and mortality, self perceived health in general and longstanding illness on the other. A connection between height and mortality has been found in other studies. ${ }^{1-3}$ To our knowledge an association between self perceived health and body height has not been shown before.

As it has often been shown that socioeconomic group, based on occupation, covaries with mortality, and as it has been suggested that height might affect the socioeconomic group of the individual, ${ }^{11} 12$ we controlled for adult socioeconomic group in the analysis. The differences in mortality were reduced by this, but only slightly. This probably means that the connection between height and mortality is established when young, and is not an effect of factors related to socioeconomic status during adulthood. This is in line with the hypothesis developed by, among others, Forsdahl, that living conditions during childhood could precondition adult health. The strong associations with the whole group of cardiovascular diseases and coronary heart disease in particular is in line with his results. ${ }^{13}$

The simultaneous standardisation for childhood and present socioeconomic group reduced the differences further, but did not eliminate them completely. This leaves us with the suggestion that the residual association between height and mortality is dependent on factors in the childhood environment which could not be controlled for by our standardisation for father's socioeconomic group. Alternatively, there could be a common genetic factor, contributing to both body height and risk of early death in adulthood.

Knight examined in his work on heights and weights of adults in Great Britain whether the average height among those reporting longstanding illness was less than for those without such complaint. This was found to be true for men but not for women. ${ }^{6}$

In our study the shortest group had the largest proportion of persons reporting longstanding illness. This trend was, however, more pronounced among women than among men and the difference was almost totally abolished when adult socioeconomic group was taken into account. The addition of childhood socioeconomic group to the analysis did not affect the results. This suggests that the connection between longstanding illness and height is not dependent on conditions during childhood (other than those closely connected to adult socioeconomic group).

The most subjective of the two self reported measures is perhaps self perceived health in general. This showed a pattern that was similar to that of mortality. As far as we know, this has not been reported earlier, although Welin et al ${ }^{14}$ suggest that self perceived health may predict mortality. The connection between self perceived health and height gives further support to the suggestion put forward by, among others, Sally Macintyre, ${ }^{5}$ that height might be a measure usable when studying the variation of general health in populations.

The evidence from this study is that the risk of early death in adulthood associated with height is small. For coronary heart disease the risk seems more substantial, although the estimate of the size of that risk is uncertain. However, because we are talking about groups that consist of a third of the population, the numbers of deaths (all causes) attributable to the underlying risk factors will be very large. If we assume that the excess risk for the shorter third of the population is about $5 \%$ and the reduced risk for the taller third is $10 \%$, after controlling for the influence of present socioeconomic status (as is the case in table 1, SMR2), the estimated attributable risk (aetiological fraction) will be $6-8 \%$. Thus, of the 52000 deaths occurring in the age group 20-79 years in Sweden in 1984 something like $3000-4000$ deaths may be linked to risk factors rooted in the childhood environment. This is the same number of deaths caused by, for example, lung and colon cancer together during that year and in the same age groups. However speculative this calculation may seem it should give an indication 
that the childhood environment is also of great importance for adult health. The risk attributable to height could be compared to the risk attributable to present socioeconomic group. If calculated on this sample it amounts to about $20 \%$.

This study was supported by the Committee for Social Research of the Swedish Health Ministry in the form of a research grant (F 87/122).

We would specially like to thank the head, Urban Janlert, and the staff of the Department of Community Medicine in Luleå, Sweden, who have given a lot of practical and intellectual support to one of us, $M$ N-P.

Address for correspondence and reprints: $\mathrm{Dr} \mathbf{M}$ Nyström Peck, Department of Community Medicine, Köpmangatan 36 B, S-951 32 Luleå, Sweden.

\section{References}

${ }^{1}$ Marmot, MG. Social inequalities in mortality: the social environment. In: Wilkinson RG, ed. Class and health: Research and longitudinal data. London: Tavistock, 1986.

${ }^{2}$ Notkola V, Punsar S, Karvonen MJ, Haapakoski J. Socioeconomic conditions in childhood and mortality and morbidity caused by coronary heart disease in adulthood in rural Finland. Soc Sci Med 1985; 21: 517-23.
${ }^{3}$ Waaler HTH. Height, weight and mortality. The Norwegian experience. Acta Med Scand 1984, Suppl 679.

${ }^{4}$ Nyström Peck AM, Vågerö DH. Adult body height and childhood socioeconomic group in the Swedish population. J Epidemiol Community Health 1987; 41: 333-7.

${ }^{5}$ Macintyre S. A review of the social patterning and significance of measures of height, weight, blood-pressure and respiratory function. Soc Sci Med 1988; 27: 327-37.

${ }^{6} \mathrm{Knight}$ I. The heights and weights of adults in Great Britain. Office of Population Censuses \& Surveys, Social Survey Division. London: HMSO, 1984.

${ }^{7}$ Social report on inequality in Sweden. Distribution of welfare at the end of 1970 s. Official Statistics of Sweden. Stockholm: NCBS, 1981. (Living conditions, No 27)

${ }^{8}$ Socioekonomisk indelning (SEI). Meddelanden i samordningsfrågor 1982:4. Stockholm: Statistiska Centralbyrån, 1983.

${ }^{9}$ Rothman K, Boice I. Epidemiologic analysis with a programmable calculator. Boston: Epidemiology Resources, 1982.

${ }^{10}$ Rothman K. Modern epidemiology. Boston: Little, Brown, 1986.

${ }^{11}$ Schumacher A, Knussmann $\mathbf{R}$. Are the differences in stature between social classes a modification or an assortment effect? J Hum Evolution 1979; 8: 809-12.

12 Bielicki T. Body height and upward social mobility. Ann Hum Biol 1983; 10: 403-8.

${ }^{13}$ Forsdahl A. Are poor living conditions in childhood and adolescence an important risk factor for arteriosclerotic heart disease? Br J Prev Med 1977; 31: 91-5.

14 Welin L, Tibblin G, Svärdsudd K. et al. Prospective study of social influences on mortality. Lancet 1985; ii: 915-8. 